\title{
PolítICA, PUnIÇÃO E SILENCIAMENTO: AS OPOSIÇÕES DE INSPIRAÇÃO MAOÍSTA EM PoRTUgal DIANTE DA REPRESSÃO (1964-1974)
}

\author{
Miguel Cardina* \\ miguelcardina@ces.uc.pt
}

Resumo: Este artigo busca analisar, em primeiro lugar, o modo como a esquerda portuguesa de matriz maoísta lidou, entre 1964 e 1974, com a chamada "questão do porte", ou seja, do "falar" ou "não falar" em contexto de prisão e tortura. Por outro lado, pretende-se demonstrar como este tema permaneceu no tempo e quais as relações que, através dele, se podem estabelecer entre tortura, silêncio e memória. Por fim, procura-se evidenciar como os conflitos entre maoístas e comunistas no interior da cadeia se enquadravam na dinâmica de dissídio ideológico que opôs ambas as correntes durante aqueles anos.

Palavras-chave: Estado Novo, Portugal, tortura, silêncio, memória, maoísmo.

Em 1976, o PCP (R) [Partido Comunista Português (Reconstruído)] ${ }^{1}$ decidiu levar a cabo uma autodenominada "Campanha de Proletarização e Revolucionarização". Um dos componentes dessa campanha consistiu na realização de inquéritos a militantes que tinham estado presos durante a ditadura. Foram sujeitos a análise 150 casos, tendo-se concluído que cerca de metade diziam respeito a "motivos não políticos ou políticos mas sem consequências do ponto de vista da apreciação do porte". Dos 74 casos restantes, detectaram-se 34 casos de "mau porte" que foram sancionados de maneira diferenciada: alguns ativistas foram recuperados como militantes, outros despromovidos à condição de simpatizantes, outros ainda tiveram como destino a expulsão (Relatório da Comissão de Inquérito à $5^{a}$ Reunião Plenária do Comité Central, s.d.).

Sensivelmente, pela mesma altura, alguns ficheiros à guarda da Comissão de Extinção da PIDE/DGS (Polícia Internacional de Defesa do Estado/Direcção-Geral de Segurança) desapareceram, ou foram amplamente

\footnotetext{
* Investigador do Centro de Estudos Sociais da Universidade de Coimbra. Pós-doutorando no Instituto de História Contemporânea da Faculdade de Ciências Sociais e Humanas da Universidade Nova de Lisboa.
} 
espoliados. No contexto conturbado da dissolução daquela estrutura policial, muitos ativistas tiveram mesmo a possibilidade de trazer para casa o seu processo, porventura com receio do que por lá pudesse estar contido, ou na convicção de que o passado de cada um apenas a cada um pertence. Esta última ideia esteve, aliás, bem presente nos debates que antecederam a abertura dos arquivos da PIDE/DGS à consulta pública. Em 1996, chegou a ser debatido no Parlamento a devolução aos próprios de cartas, fotografias e outros documentos pessoais apreendidos pela PIDE. A decisão prevalecente foi, porém, no sentido de nenhuma documentação ser devolvida e o arquivo está hoje, com algumas restrições, disponível para consulta na Torre do Tombo, em Lisboa. ${ }^{2}$

O que parece relevante sublinhar em ambos os episódios é o fato de eles mostrarem bem como o passado pode ser não apenas uma sombra da qual nos vamos afastando, mas um fantasma cujas marcas dificilmente se diluem no tempo. Embora a conjuntura política e social tenha mudado com o 25 de Abril, as experiências traumáticas vividas em contexto de interrogatório e tortura não se desdramatizaram profundamente com a mudança de regime. A urgência em fazer a revolução e a maneira como as estruturas partidárias à esquerda lidaram com a questão ajudam a perceber isso; mas os motivos também devem ser procurados na evidência de que os efeitos da tortura no corpo e na alma dos antigos prisioneiros não desaparecem por decreto. Entre outros aspectos, a notória dificuldade dos presos em comunicar ainda hoje as suas experiências de cárcere é disso um reflexo.

\section{SILÊNCIOS E PODER}

A temática do silêncio tem vindo a ser analisada na sua conexão com o poder. Se frequentemente essa relação é vista sob o prisma da imposição - o silêncio como resultado de uma coação externa que dissipa os indivíduos e as coletividades -, a verdade é que o silêncio também pode ter uma dimensão positiva, enquanto veículo para o exercício do poder e cerne de experiências de identificação. Maria-Luisa Achino-Loeb, em uma feliz definição, classifica-o como uma "experiência da presença disfarçada de ausência" (Achino-LoeB, 2006, p. 2). O silêncio e as suas modalidades têm, com efeito, um carácter ambíguo e situacional que aparece de modo muito evidente no tema da repressão e tortura aos presos políticos.

A vertente negativa do silêncio, o silêncio-imposição, é analisada por Françoise Sironi em um estudo psicológico sobre a tortura. Para a autora, a tortura não se propõe apenas a extorquir informação, mas sobretudo silenciar 
as vítimas e o grupo ao qual elas pertencem (SIroni, 1999). Silencia, em primeiro lugar, porque a dor monopoliza a linguagem, ao mesmo tempo que resiste à "objetivação linguística", devido ao fato de não dispor de um referencial exterior. Mesmo quando os torturadores não eliminam a voz de forma permanente através da mutilação ou do assassínio, domesticam-na de modo a operar uma desagregação das estruturas de significado (SCARRY, 1985, p. 4-5). Daí que algumas estratégias de cura tenham sido desenvolvidas precisamente em torno da capacidade de narrar a sua experiência. É o caso do "método do testemunho", criado pelos psiquiatras dinamarqueses Inger Agger e Soren Jensen, a partir do trabalho com mulheres refugiadas chilenas na Dinamarca (Weine, 2006, p. 5-24).

Em uma investigação sobre as consequências clínicas dos interrogatórios da PIDE/DGS levada a cabo logo a seguir a 1974, o psiquiatra Afonso de Albuquerque também notara que, mais do que fazer falar, interessava à polícia política desapossar o preso da sua identidade e silenciá-lo por meio da tortura (AlbuQuerque, 1987). A tortura induzia ao silêncio na justa medida em que incitava à palavra: "falar" na PIDE, para além de conceder provas passíveis de condenação em tribunal e de facilitar a perseguição e detenção de companheiros, significava calar o sujeito que se era. O caso de Francisco Martins Rodrigues, o principal teórico do maoísmo português nos anos sessenta, é exemplar a esse respeito.

No contexto das discussões em torno do conflito sino-soviético, Francisco Martins Rodrigues fora expulso do Partido Comunista Português em dezembro de 1963 e criara, poucos meses depois, a Frente de Ação Popular (FAP) e o Comité Marxista-Leninista Português (CMLP). Exilado em Paris, decidiu entrar clandestinamente em Portugal em 1965, juntamente com Rui d'Espiney e João Pulido Valente, os restantes elementos do secretariado da organização. Com a estrutura ainda em fase de implantação, a PIDE viria a prender alguns dos seus elementos, entre os quais João Pulido Valente, que fora denunciado por Mário Mateus, um agente policial infiltrado na FAP/ CMLP. Em "julgamento revolucionário" realizado a 26 de novembro de 1965, no pinhal de Belas, perto de Lisboa, Francisco Martins Rodrigues e Rui d'Espiney decidiram executar Mateus, sendo capturados pela PIDE no início de 1966.

Ambos foram submetidos a intensas sessões de tortura e viriam a confirmar alguns nomes à polícia. Francisco Martins Rodrigues recorda que, em tribunal, a PIDE juntou aos autos uma série de folhas de forma a poder compor o conjunto da organização pela voz do seu máximo responsável. Mas significativo é o modo como acaba por concluir: "o essencial é que eles tinham 
conseguido sacar informações e reduzir um gajo àquilo que eles queriam: a partir de agora este homem está arrumado" (RodRIGUEs, 29/1/2008). "Estar arrumado" não significava apenas sujeitar-se ao desprezo dos camaradas. Era, em última análise, tomar consciência de que fora vítima de um processo de despotenciação política. Assim se compreende que alguns militantes "marxistas-leninistas" (m-l), incapazes de cumprir a diretiva de nada dizer à polícia, tenham anunciado em julgamento que isso lhes havia subtraído a condição de "militante comunista integral" (Defesa de Rui d'Espiney, s.d.; Rodrigues, 2008, p. 79).

Entendia-se, em última análise, que a condição de "comunista integral" exigia a armadura de um corpo militante, capaz de suplantar a dor por meio de uma forte consciência ideológica. Isso é descrito, de forma pungente, por um preso político em uma autocrítica enviada para o exterior da cadeia.

Quis lutar com as armas que tinha, e lutar ainda depois de ter sabido, pela derrota do meu corpo e pela perda da minha lucidez que a força era pouca, fraca e frágil, e que a resistência só poderia ser vitoriosa se tivesse sido maior, mais intenso, integral o meu empenho no projeto revolucionário, integral a preparação técnica, física e ideológica, integralmente comunista o corpo, como pretendia tornar-se a inteligência. (ANTT/PIDE/DGS, PC 679/68, NT 6007)

Privação do sono, "estátua", espancamentos, insultos e chantagens foram os métodos de tortura mais usados pela PIDE/DGS. ${ }^{3}$ Rui d'Espiney denunciou a violência física e psicológica a que foi sujeito na sua defesa em tribunal:

Desde a tortura pelo sono - de forma que só de uma vez me obrigaram a ficar 190 horas sem dormir - ao uso de drogas - como se tem de concluir do fato de eu haver passado (durante o "sono") de estados de enorme prostração para estados de grande vivacidade e vice-versa, quase sem transição; desde o espancamento a murro e a pontapé, com cacetes e com uma cadeira - no que se destacaram, pela sua particular ferocidade, o Inspetor Cardoso e os agentes Inácio Afonso e Pereira André - aos insultos mais nojentos; desde as ameaças de morte (o subdiretor Sachetti garantiume várias vezes que me abateria e a minha mulher e a Francisco Martins Rodrigues, e o Inspetor Cardoso chegou mesmo a procurar intimidarme com uma navalha), às habituais tentativas de compra e humilhação, todos os métodos foram considerados bons para me quebrarem. (Defesa de Rui d'Espiney, s.d.). 
Muitas dessas torturas eram aplicadas em simultâneo. Veiga de Oliveira, militante do PCP, foi torturado durante 37 dias, tendo estado 17 dias na "estátua", ao mesmo tempo que era espancado e molestado com um cassetete eléctrico. Após um dia a dormir, foi novamente submetido à tortura do sono por dois períodos de dez dias, até que entrou em coma (Oliveira, 1994). Acácio Barata Lima, preso com Francisco Martins Rodrigues em 1966, afirmou ter sido submetido a dois períodos de tortura do sono - de quatro dias, o primeiro, e de uma semana, o segundo - que eram acompanhados de espancamentos com a participação dos inspetores Óscar Cardoso, Pereira André e Inácio Afonso e a supervisão de um médico, de modo a que a tortura pudesse ser duradoura, minimizando os riscos de o preso falecer às mãos da PIDE (AHM, 4º TMT-Lisboa, proc. 118/76, pasta 6 , arquivo 70, fl. 62). Como se pode constatar - através da consulta à documentação produzida pela Comissão Nacional de Socorro aos Presos Políticos - os casos de privação de sono e "estátua" acompanhados de espancamentos eram bastante comuns. ${ }^{4}$

Não é irrelevante que as agressões começassem frequentemente pela simples recusa do sujeito à sua imagem. $\mathrm{O}$ corte da barba e do cabelo, a confiscação de bens pessoais, a negação de hábitos de higiene e a ausência de espelhos eram já formas de criar fraturas no interior dos indivíduos. Um outro método de tortura muito usado pela PIDE/DGS consistia no simples isolamento, mais eficaz do que pode parecer à primeira vista e responsável por grande sofrimento psicológico. Pinto de Sá - que representa um exemplo extremo e diferente de alguém que depois de preso passou a colaborar ativamente com a polícia política - afirmou sentir uma "ansiosa necessidade de falar" após os vinte e um dias de isolamento (SÁ, 2006, p. 206). ${ }^{5}$ Álvaro Cunhal chegou mesmo a referir ao isolamento como "a pior das torturas". No seu estudo sobre a PIDE/DGS, Irene Pimentel cita a descrição de J. A. Silva Marques, que o considerou como "muito mais abalador que a mera violência física". E acrescentava:

Uma reacção significativa era a dos presos em "isolamento" chamados a interrogatório. Como se ansiava dia a dia essa chamada. Ir a interrogatório era como que ir ver o que se passava "lá fora". Um regresso ao mundo. E quando se ouvia no corredor os passos da brigada que vinha buscar um preso para interrogatório, e ela se dirigia para a cela ao lado, sentia-se uma amargurada mistura de alívio e frustração. A "sorte" de não ter ido, de não suportar provavelmente novos vexames ou violências; $\mathrm{e}$ o não ter tido a "sorte" de ir, de ir "lá fora". (Apud Pimentel, 2007, p. 371) 
Uma das funções do isolamento era a de fazer crescer a expectativa da dor. Como a CIA já havia notado no relatório Kubark, de1963, a expectativa da dor podia ser bem mais eficaz do que a dor realmente infligida. Se a brutalidade física tende a criar "ressentimento, hostilidade e maior desafio", podendo até ser recebida com "alívio", a "ameaça de infligir dor pode gerar medos mais perturbadores do que a própria sensação de dor", diz-se (apud ANDRINGA, 2009). É isto, aliás, que se passa na Sala 101 do famoso romance Mil novecentos e oitenta e quatro, de George Orwell ([1949]1997): apesar de ter aguentado inúmeros espancamentos, é quando Winston se confronta com a proximidade insuportável das ratazanas que denuncia a sua companheira Júlia.

Por outro lado, a tortura silencia porque instala igualmente um clima de medo que visa paralisar a resistência. Aciona-se, assim, aquilo que Hermínio Martins chamou de "coeficiente ótimo de terror" que o Estado Novo português soubera aplicar, e que consistia em dosear a violência de forma precisa e localizada de modo a que se propagasse um efeito dissuasor (MARTINs, 1998). Também Fernando Rosas apontou a cuidadosa gestão feita pelo regime entre "violência punitiva" e "violência preventiva", notando como ambas se calibravam de acordo com as circunstâncias e as possibilidades (MAdeira et. al., 2007, p. 26-30). O que significa que a tortura, apesar de escondida e negada pelos seus executores efetivos e morais - a consulta aos arquivos da PIDE/DGS é uma viagem perturbadora a essa omissão - não deixou de ser um pilar fundamental na durabilidade do regime.

\section{A voz DA víTIMA}

Nessa medida, o testemunho dos intervenientes é fundamental para se poder conhecer essas margens da história sobre as quais a documentação escrita, proveniente dos arquivos oficiais, pouco revela. E isso é ainda mais importante porque o silêncio imposto no corpo e na alma do prisioneiro permanece sob múltiplas formas. Ao lado do silêncio das vítimas que são incapazes de nomear o horror vivido nas salas de tortura, há também o silêncio daqueles que não se conseguiram manter em silêncio. Com efeito, nas dezenas de ativistas contactados, poucos se dispuseram a falar dessa questão, contornando-a explícita ou implicitamente. Aqueles que sobre ela falaram, fizeram-no muitas vezes de maneira indireta ou rígida - com expressões como "já tinha lido sobre o assunto, mas estar lá é diferente", ou informando, sem mais, dos tipos de tortura a que foram submetidos e do número de dias que a sofreram. Houve mesmo quem tenha colocado tabu 
sobre o tema como contrapartida para a conversa, estipulando um espaço de resguardo íntimo que tratava de manter inviolável. Tal como Michael Pollak enunciou nos seus estudos com mulheres que estiveram em campos de concentração nazis, o silêncio pode não ter origem no esquecimento, mas, sim, na lembrança de um episódio traumático que se decide não exprimir por palavras, e que participa naquilo a que o autor chama "gestão do indizível" (Pollak, 1993).

Importa notar que a entrevista, enquanto acesso à experiência subjetiva, faz ela própria parte do processo de "perpétua elaboração da identidade" (Branche, 2001, p. 44). Ao abordar criticamente a noção de "histórias de vida", também Pierre Bourdieu (2006) falou do perigo da "ilusão biográfica", essa crença de que existe uma coerência perfeita em uma dada trajetória pessoal. Em sentido semelhante, Fernando Catroga alertou para o modo como o cariz teleológico da recordação entende o "percurso autobiográfico como se fosse um continuum, cuja coerência existencial unifica os buracos negros da caminhada". Os sujeitos tenderiam assim a traçar enredos que domesticam "o aleatório, o casual, os efeitos perversos e descontínuos do real-passado quando este foi presente" (CATroga, 2001).

Em um texto já clássico no campo da história oral, Alistair Thomson (2006) afirma que os relatos de vida tendem a seguir uma lógica de "composição"; buscam os indivíduos coerências narrativas entre passado, presente e futuro, o que os faz reprimir ou rever memórias dolorosas que não se acomodam facilmente à sua identidade atual, ou que revelam tensões e traumas ainda não resolvidos. Tal não significa que o historiador tenha de ficar refém desse silêncio, ou que os recalcamentos sejam impenetráveis à sua compreensão. Algo do gênero está presente no caso de um antigo ativista contactado no decurso do estudo e que declarou o seu "porte exemplar" na polícia; isto apesar de a consulta ao processo na PIDE/DGS apontar em sentido diverso. Esse exemplo mostra bem como o presente não deixa de estruturar os discursos que os sujeitos elaboram sobre o seu passado. Independente da questão de saber se acredita efetivamente na sua narrativa, ou quais as razões que a podem explicar - vergonha? vaidade? noção de que se sofreu suficientemente para reivindicar o estatuto de "herói"? indecifrável corrupção policial dos autos? -, esse episódio sugere como, em certa medida, a perseguição, a tortura e a prisão não expiraram com a queda da ditadura e se refletem ainda hoje no corpo e na mente de antigos ativistas políticos. 
A QUESTÃO DO PORTE

É preciso ter em conta que o "mau porte" foi muitas vezes motivo de expulsão das organizações e de ostracismo junto de camaradas e amigos. $\mathrm{O}$ padrão de comportamento dominante adotado pelos "marxistas-leninistas" inspirava-se na posição do PCP, que havia estabelecido como regra a recusa a fazer qualquer declaração e a assinar qualquer documento na polícia. Segundo José Pacheco Pereira, o primeiro preso político a tomar essa atitude foi Francisco Miguel, em dezembro de 1939. A atitude de Francisco Miguel viria a inspirar a reflexão de Cunhal no documento Se fores preso, camarada, editado em abril de 1947, no qual se estabelecem "regras de comportamento dos comunistas presos, muito mais severas do que aquelas que existiam em movimentos revolucionários clandestinos nos outros países" (Pereira, 1999, p. 389).

No entanto, a argumentação aduzida para o ato de "não falar" é diferente. Logo em outubro de 1965, a FAP/CMLP criticou o PCP por abordar a questão do ponto de vista da honradez e da lealdade, utilizando para isso conceitos católicos como inferno, paraíso e purgatório, em vez de colocar o comportamento na PIDE, no contexto da luta entre burguesia e proletariado. Também o PCP (m-l) [Partido Comunista de Portugal (marxista-leninista)] criado em 1970, em França, a partir do antigo CMLP - considera Se fores preso, camarada como um documento marcado por um "espírito catequista", apesar de conter "dados úteis sobre diversos tipos de tortura utilizados e dos fins com que a PIDE os utiliza" (O Novo Militante, n. 10, 1974).

Mais do que um reflexo da capacidade individual de resistência do preso, ou até da persistência dos laços afetivos e de companheirismo, o "bom porte" seria o resultado de uma linha política justa e consequente. Essa linha de análise viria a ser utilizada indistintamente pelos grupos maoístas. Segundo o PCP (m-l), a temática do porte pode ser lida paralelamente ao processo de degenerescência que o PCP teria sofrido a partir de 1956 (O Novo Militante, n. 6, 1973). Em 1973, e após alguns casos de traição e delação nas suas fileiras, os Comitês Comunistas Revolucionários (marxistas-leninistas) consideraram que "o interrogatório policial é um dos aspectos mais concentrados da luta de classes" e que "no aparente isolamento da sala de torturas", nem o preso nem o torcionário estão sós, mas antes acompanhados pela classe cujos interesses representam (Comunicado sobre as prisões de agosto-setembro de 1972, CCR (m-l), fevereiro de 1973). Com uma linguagem mais inflexível, o MRPP (Movimento Reorganizativo do Partido do Proletariado), fundado em setembro de 1970, veio afirmar que a "traição não se situa acima da luta 
de classes" e que ela "jamais será o fruto de torturas violentas, de debilidades físicas, de doenças", mas, sim, de "uma ideologia decadente, uma natureza de classe e uma prática social que nada têm a ver com o proletariado e o povo" (Luta Popular, n. 14, 1973). O sacrifício pessoal seria suportável por meio da devoção revolucionária:

Um revolucionário não teme a sanguinária repressão dos carrascos da burguesia porque sabe que espancamentos, torturas, queimaduras, estátua, privação do sono, a dádiva da própria vida, são pequenas gotas de água comparadas com o ar da exploração, opressão, humilhação e violência diária sobre milhões e milhões de camaradas seus! (Viva a luta dos revolucionários nas masmorras da burguesia!, Federação de Estudantes Marxistas-Leninistas, 19/9/1972)

Em regra, as organizações m-l distinguiam teoricamente entre colaboração ativa com a polícia (a "traição") e incapacidade de resistir à tortura sob intensa pressão física e psicológica que podia levar à delação ou, simplesmente, à confirmação de informações de que a polícia já dispunha. A gradação do tipo de cedências, no entanto, nem sempre era fácil de aferir e estava muitas vezes dependente das informações que os presos passavam para o exterior, ou da percepção que as organizações iam tendo a partir do nível de perseguição imediata a que eram sujeitas. Isso não impediu que algumas organizações defendessem a expulsão de qualquer elemento que tenha prestado declarações à polícia, ou criticassem os grupos que concediam o estatuto de militantes a elementos que haviam falado na polícia. A contracorrente - um grupo como O Bolchevista defendeu que considerar que "os maus portes são a aniquilação total, a impossibilidade de nos reconstruirmos como revolucionários - é aceitar uma atitude metafísica e passiva" (O Bolchevista, n. 1, 1970). Foi por isso mesmo criticado por outras organizações $\mathrm{m}$-l, tendo feito posteriormente uma autocrítica dessa sua posição (O Bolchevista, n. 7, 1971).

O SILÊNCIO DIFÍCIL

A busca da confissão por parte da polícia não correspondia só à tentativa de recolher provas incriminatórias. Tratava-se igualmente de estilhaçar a identidade militante, colocada em causa pelo "fraquejamento" diante do torcionário. Se falar diante da PIDE correspondia a uma "quebra", resultando no silenciamento do "revolucionário", silenciar-se em interrogatório e tortura significava a sonora afirmação do heroísmo exigido. Em sede de 
interrogatório, este silêncio manifestava-se na recusa em responder às perguntas dos inquisidores e em assinar posteriormente os autos. Foram várias as estratégias acionadas para manter o silêncio, mas passavam invariavelmente por manter a lucidez e o ânimo e contar, naturalmente, com uma capacidade de resistência constantemente posta à prova. João Pulido Valente relatou dessa forma a sua experiência:

Era de noite, estava muito frio e me puseram todo nu numa sala de interrogatórios, cheia de pides. Obrigaram-me a ficar de pé e eu, para não falar, optei sempre por responder a mesma coisa: "recuso-me a prestar declarações". Como tenho facilidade em vomitar, resolvi provocar vômitos para ficar cada vez mais debilitado. A minha ideia era destruirme fisicamente e manter-me lúcido. Ficar sem raciocínio, concentrado na ideia de não falar. Um deles achou que o melhor era dar-me leite e eu pedi um balde: bebi litros de leite e vomitava tudo a seguir.

Fiquei primeiro oito ou dez dias na tortura do sono, depois uns dias de intervalo e outra vez vários dias sem dormir. Fui espancado umas vezes, com pontapés e socos. Cheguei a um tal estado que o médico deles aconselhou-os a retirar-me porque eu estava em risco de vida.

Durante todo o tempo dos interrogatórios, apareceu por lá o pide Óscar Cardoso a fazer de bonzinho, e à noite aparecia também o Sachetti, todo perfumado, vindo do dancing ali ao lado, a fazer-me discursos. (VAlente, 1994)

A alternância entre "pide bom" e do "pide mau" foi, como se sabe, uma das técnicas mais usadas pela polícia política. As sessões de tortura eram geralmente sucessivas de tentativas paternais de convencimento a falar. Após as brutais torturas a Veiga de Oliveira, já atrás descritas, os inspetores Sachetti e Tinoco apareceram com um bolo de aniversário e uma garrafa de whisky no seu dia de anos. Os agentes revezavam-se nas figuras do "pide bom" e "pide mau": Perez Metello registra que conheceu, em Caxias, os acusados do processo da ARA, como Carlos Coutinho, barbaramente torturados por pides que tiveram consigo posturas de delicadeza (Metello, 1994; Oliveira, 1994).

Aparecer diante do preso impecavelmente vestido e perfumado era também uma forma de lhe tentar quebrar o ânimo. A teatralização também foi usada: Rita Gonçalves recorda que o subinspector Abílio Pires um dia simulou que lhe ia bater, tendo-se gerado o seguinte diálogo: "Pensou que lhe ia bater? E eu: Sim. O quê? Eu?! Acha que batemos nas pessoas? Eu não acho, sei!" (GonçAlves, 17/1/2008). Por seu turno, Francisco Martins 
Rodrigues lembra que em uma ocasião o inspetor Inácio Afonso o obrigou a despir-se e empunhou uma faca, com a qual ameaçou pôr-lhe "as tripas de fora, 'como se fazia em Angola com os pretos"'. Em outra ocasião, ter-lhe-ia mesmo passado para a mão uma pistola para o caso de querer matar-se.

A certa altura vieram vários inspetores - era de manhã, se calhar foi para se divertirem - “ah, este é que é o gajo”. Eu já estava a baralhar o sonho e a realidade, mas tenho quase a certeza que isto que vou contar aconteceu: o Inácio Afonso, que era quem mais ou menos “tratava” de mim, deu-me uma pistola para a mão, "eh pá, tu se calhar queres matar-te, guarda aí isso contigo". (RoDrigues, 29/1/2008)

A PIDE procurava explorar, sempre que possível, as situações em que os detidos, privados de sono, tinham alucinações. O conhecimento dos sintomas provocados pelo suplício podia ajudar a proteger o preso. Pedro Baptista, destacado dirigente de O Grito do Povo (Organização Comunista Marxista-Leninista Portuguesa, a partir de 1973), recorda que conhecia "de cor e salteado a patologia do torturado", o que o ajudou a suportar as alucinações, que no seu caso envolveram insetos e serenatas com música de protesto. Também nas leituras permitidas foi possível encontrar ânimo. No intervalo das torturas a que foi submetido na sede da PIDE do Porto e em Caxias, Pedro Baptista pôde ler o D. Quixote, que reputou como "um livro fundamental para a resistência de alguém que está preso", já que, "a dada altura da obra, os prisioneiros vão para as galeras e há uns que são desprezados pelos outros, e que são aqueles que sem a polícia ter provas, falaram e incriminaram por terem falado" (BAPTISTA, 16/1/2008).

As linhas de solidariedade estabelecidas com familiares, amigos e camaradas, fundamentais para a manutenção do ânimo do preso, eram alvos das forças policiais. Fazer crer que os companheiros já haviam "falado" era uma das formas através das quais a polícia procurava esboroar o pacto de silêncio estabelecido. Forjar a data de assinatura dos autos - e as próprias assinaturas - podia também fazer parte do mesmo plano, levando a que se acreditasse que o preso fraquejou de imediato. Um exemplo disso passouse com Fernanda Dâmaso. Presa a $1^{\circ}$ de maio de 1973, tem o seu primeiro auto - com as assinaturas, da detida e dos agentes, a letra muito semelhante assinado a 5 de maio. Um pequeno pedaço de papel interceptado pela PIDE permite, porém, apontar em outro sentido. A 26 de junho de 1973, a PIDE apreendeu um cigarro que Fernanda Dâmaso procurava entregar à cunhada durante a visita e onde se lia: "Continuo a ser torturada. Estive 
mais sete noites sem dormir. São já 17 ao todo". O agente informou julgar que "a cunhada não se apercebeu do que estava escrito no cigarro, por não ter tido tempo para isso". ${ }^{6}$

Aurora Rodrigues tomou contato direto com autos forjados. Nascida no Alentejo, no seio de uma família com parcos recursos econômicos, conseguira ir para Lisboa, em 1969, estudar Direito por uma feliz conjugação de acasos, esforços e vontades. Foi presa em maio de 1973, no decorrer de uma manifestação estudantil, no momento em que já era militante do MRPP com funções no aparelho técnico. Em Caxias, durante as torturas - esteve 16 dias em tortura do sono, mais 4 dias após uma interrupção de mais de uma semana - foi-lhe apresentado um conjunto de folhas com declarações que supostamente teria proferido, o que a levou a rasgá-las diante do agente que lhas apresentou. Sem confissão nem denúncia que a pudesse incriminar, foi libertada a 28 de julho de 1973 (Rodrigues, 2011).

\section{PolítICA NAS PRISÕES E “ReCONSTRUÇ̃̃o” dos MILITANTES}

A animosidade entre os militantes do PCP e da FAP/CMLP exacerbada com os episódios em torno da expulsão de Martins Rodrigues mas, sobretudo, com a informação pelo Avante! de que Pulido Valente e Manuel Claro haviam entrado no país, vista como uma denúncia objectiva à PIDE - prolongou-se para o interior do espaço prisional. ${ }^{7}$ Em Peniche, onde se encontravam os presos homens já condenados, teriam existido em um primeiro momento tentativas de unidade entre "comunistas" e "marxistas-leninistas", que rapidamente se foram esboroando. Um documento de 1970 - oriundo de "A Vanguarda", uma pequena organização maoísta portuguesa em França - nota que, entre 1965 e 1967, "a política dos marxistas-leninistas [foi] de mostrar face aos guardas que não existem aparentemente qualquer divergência entre eles e os revisionistas no plano da luta" (As lutas dos revolucionários portugueses no interior das prisões, A Vanguarda, 1970).

Em documento apreendido pela PIDE - no qual se faz a análise da atuação dos "marxistas-leninistas" presos em 1966 e se apontam linhas estratégicas para o futuro - estipula-se logo aí a necessidade de divergência com os presos do PCP. Reitera-se o imperativo de manter uma posição de distanciamento em relação aos dirigentes "revisionistas" a aos "elementos democratas liberais", e criticam-se alguns camaradas por se terem deixado "envolver até certo ponto nas palavras e atitudes unitárias dos revisionistas". A tarefa deveria ser "desmascarar, isolar e dividir os revisionistas como 
agentes da burguesia junto do movimento operário" (Algumas experiências da atividade na cadeia em 1966, ANTT, PIDE/DGS, PC 1397/67, NT 5933).

$\mathrm{Na}$ análise efetuada, distingue-se entre dirigentes e trabalhadores de base, mesmo que afetos ao PCP, afirmando que o esforço de unidade devia ser feito com estes, mas na base de um apoio à revolução chinesa e à ideia de reconstrução do partido. O texto, porém, é bastante crítico sobre os resultados práticos que teriam sido alcançados, apontando-se duas razões maiores para $\mathrm{o}$ fracasso. Em primeiro lugar, o fato de os presos $\mathrm{m}$-l estarem com "dirigentes revisionistas no mesmo lado da trincheira, conduzindo uma luta comum e diária contra os carcereiros fascistas", o que os fazia momentaneamente esquecer "que os revisionistas não são comunistas em erro, mas uma corrente burguesa". A segunda razão tocava precisamente na questão do porte:

Bastantes camaradas sentem-se diminuídos em face dos responsáveis revisionistas, devido à larga experiência política destes, ao seu passado, ao seu porte firme na polícia, ao fato de ainda serem considerados por muita gente como comunistas. Esses camaradas, diminuídos pelos seus pontos fracos (baixa cultura política, inexperiência, mau porte na polícia), não se atrevem a conduzir uma luta ideológica e política ativa contra os revisionistas, esquecendo que qualquer militante que segue a linha comunista está sempre acima do revisionista que luta contra a revolução; tudo o mais são fatores secundários. (Algumas experiências da atividade na cadeia em 1966, ANTT, PIDE/DGS, PC 1397/67, NT 5933)

Não deixa de ser significativo que o "mau porte" na polícia apareça junto de fatores como a baixa cultura política e a inexperiência, todos eles reputados de secundários em relação à linha política seguida. O fato de uma parte considerável dos presos da FAP/CMLP não ter conseguido manter até o fim uma postura intransigente no confronto com a PIDE/ DGS ajuda a explicar isso. O que não significa, porém, que a questão tenha sido efetivamente secundarizada. Francisco Martins Rodrigues, por exemplo, apesar de continuar a ser reconhecido como o principal teórico da corrente, recordou que não fomentava contatos com os grupos no exterior, já que entrou em um processo de autolimitação em função de ter "falado" (Rodrigues, 29/1/2008). A consciência de culpa teria servido de eixo a discussões sobre os caminhos a adotar para a "reconstrução" futura dos militantes:

Houve um debate sobre se nos deveríamos proletarizar ou não após a saída. No meu ponto de vista, isso tem muito a ver com o fato de grande 
parte dos presos deste grupo não ter tido na cadeia o comportamento que era exigido organizacionalmente, logo, que teriam de fazer alguma reabilitação. Para alguns - lembro-me que o Francisco Martins Rodrigues defendia isso - essa reabilitação passava por um processo de proletarização, pelas pessoas assumirem de fato uma vida de operários. Não serem "intelectuais pequeno-burgueses", usando a linguagem da época. Nesse coletivo, quem se opunha fundamentalmente a isso era o João Pulido Valente que achava, por um lado, que era difícil às pessoas com formação de base intelectual se inserirem nesse meio sem parecerem estranhas, sem se denunciarem, e, por outro, se existisse uma revolução as pessoas seriam mais úteis nas suas profissões de caráter técnicocientífico mais avançado, digamos assim. O médico deveria continuar a ser médico, o engenheiro deveria continuar a ser engenheiro e por aí fora. (HENRIQues, 3/1/2008)

A tensão entre comunistas e "marxistas-leninistas" manifestou-se de várias maneiras: entre outubro de 1966 e fevereiro de 1967, surgiram altercações quanto às datas revolucionárias a comemorar. Se todos comemoravam - embora não conjuntamente - o $1^{\circ}$ de Maio, a extremaesquerda celebrava ainda o 18 de Janeiro (insurreição na Marinha Grande, em 1934), o $1^{\circ}$ de Outubro (aniversário da Revolução Chinesa de 1949), a Revolução Russa de outubro (a 7 de novembro) e o 4 de Fevereiro (início da luta armada em Angola), enquanto censuravam os militantes do PCP por comemorarem o 5 de Outubro (implantação da República) e o $1^{\circ}$ de Dezembro (restauração da Independência) (As lutas dos revolucionários portugueses no interior das prisões, A Vanguarda, 1970).

No entanto, foi na atitude a ter perante os guardas e o estabelecimento prisional que se registraram as maiores divergências, o que viria a ter reflexos claros nas greves da fome conduzidas a partir de 1970 pelos presos mais radicais; greves essas que não contaram com a solidariedade dos comunistas. Um texto da corrente m-l data de 1968 o agudizar das posições, com o "rompimento da luta contra a permanência dos guardas nos refeitórios", a recusa de abandonar as visitas após um preso ter a sua interrompida e a "tentativa de moderação da luta desencadeada pelo espancamento de um camarada". Estipulando-se então que os "revisionistas" eram "inimigos de classe - não apenas no plano teórico e abstrato, mas em todas as posições práticas" -, decide-se impor o tratamento por você aos "elementos dirigentes revisionistas", abolir os jogos e a leitura conjunta do jornal em voz alta, não participar em festejos de aniversário ("reflexo declarado de uma ideologia 
burguesa"), manter o afastamento das festas religiosas, não festejar em comum o $1^{\circ}$ de Maio e fazer uma completa separação de dinheiro.

Essa última proposta articulava-se com um estilo de vida que os prisioneiros maoístas procuravam incentivar. Tratava-se de criar comunas revolucionárias que não admitissem as "diferenças materiais cada vez mais marcadas entre os presos". A comuna deveria passar para propriedade coletiva todos os bens - dinheiros, alimentos, roupas, livros - governando segundo o princípio comunista "de cada um segundo as suas possibilidades, a cada um segundo as suas necessidades". A proposta redigida aponta claramente que o objetivo da comuna não consiste em "elevar os presos pobres ao nível dos ricos, mas, pelo contrário, baixar o nível dos ricos e criar condições de vida que se aproximem do nível médio do proletariado". Para isso seria necessário suprimir "gastos supérfluos (banquetes, artigos de luxo, festas de aniversário)", mas admitindo que a reeducação dos elementos burgueses deveria ser feita de forma gradual (ANTT/PIDE/DGS, PC 2645/65, NT 5795-5796, v. 3).

Entretanto, as greves da fome e as lutas e reivindicações em geral, feitas pelos presos das várias tendências políticas, foram tornando a vida prisional menos dolorosa. Na segunda metade da década de 1960, os prisioneiros já podiam conversar em grupo, praticar jogos variados, como voleibol, e aceder a uma sala de convívio com rádio. Para o comunista Fernando Miguel Bernardes, o regime manteve-se tenso mesmo após a entrada em cena de Marcelo Caetano: a alimentação não melhorou, conservou-se o castigo do isolamento no "segredo" e ainda era proibido ir à retrete durante a noite. Só com a nomeação de um novo diretor da cadeia em 1973 - "um homem ainda jovem, licenciado em Direito e de ideias consideradas, nas circunstâncias, bastante abertas" - se atenuou significativamente a dureza das condições de encarceramento. As possibilidades de circulação dos presos aumentaram, melhorou a alimentação e foi colocado um televisor na sala de convívio (Bernardes, 1991, p. 135-147). A isso, é óbvio, não seriam alheias as lutas desenvolvidas pelos presos, a movimentação dos familiares e a ação de coletivos como a Comissão Nacional de Socorro aos Presos Políticos que, exaustivamente, denunciava a existência de presos políticos em Portugal.

\section{DE ABRIL DE 1974}

A 25 de abril de 1974, as movimentações libertadoras não chegaram imediatamente ao conhecimento dos presos políticos. O comunista Fernando Miguel Bernardes relata que nesse dia os guardas não concederam visitas e 
a rádio permanecia calada, e só aos poucos os presos se foram apercebendo da situação insurreccional. Ao raiar da manhã de 26 de abril, os presos de Peniche continuavam no interior da Fortaleza. A meio da noite de 26 para 27, os prisioneiros foram ouvidos pelos representantes oficiais das Forças Armadas, enviados pela Junta de Salvação Nacional, e começaram a sair em liberdade (BERNARDES, 1991, p. 142-147).

A presença de três presos condenados por crimes de sangue Francisco Martins Rodrigues e Rui d'Espiney, da FAP/CMLP, e Filipe Viegas Aleixo, da LUAR - fez com que a libertação sofresse demoras, já que ordens de Spínola impunham que esses elementos se mantivessem detidos. A memória do que se passou a seguir difere consoante a área política. Fernando Miguel Bernardes nota que a maioria dos presos se recusou expressamente a "sair sem a garantia de que nem um preso político ficasse entre as grades", não identificando qualquer conflito entre os presos (BERNARDES, 1991, p. 146). Rui d'Espiney e Francisco Martins Rodrigues, por sua vez, evocam a solidariedade em assembleia dos presos da área da extrema-esquerda que se recusaram a sair enquanto lá ficasse algum dos condenados por "crimes de sangue". O primeiro recorda que a assembleia apenas teve a presença dos presos do rés do chão e do $1^{\circ}$ andar: "por cima estavam os presos do PC. Aí as coisas foram completamente diferentes: quando chegou a hora de serem libertados, foram libertados" (D'EsPINEY, 1/7/2008). Martins Rodrigues afirma também que os presos do PCP começaram a sair - o próprio Viegas Aleixo estava no piso dos comunistas e veio se juntar a eles - e que foi o grupo dos presos $\mathrm{m}-\mathrm{l}$, da LUAR e anticoloniais que tomou a atitude de intransigência (RodRigues, 29/1/2008). Segundo os presos m-l, esse episódio inseria-se na linha de falta de solidariedade dos presos comunistas às lutas efetuadas no interior da cadeia; para esses, por seu turno, a prática de constante afrontamento aos guardas e à direção da cadeia, em parte, provocava um ambiente de irritação que inviabilizava as pequenas conquistas.

A diferenciação perante o campo da militância comunista aparece, assim, como um dos eixos centrais da construção da subjetividade política dessa área radical associada ao maoísmo. Por outro lado, e não obstante algumas variações discursivas, esse terreno político estipulou comportamentos em situação de tortura e encarceramento que se filiavam diretamente na tradição que o PCP vinha afirmando desde finais da década de 1930. A extrema dureza da norma genérica de nunca prestar declarações à polícia e o opróbrio, mais ou menos acentuado, a que estavam sujeitos todos os que "fraquejavam" fizeram com que se produzissem processos de autolimitação, culpa e silenciamento que ainda hoje são difíceis de 
desbloquear. É como se, ironicamente, a ditadura tivesse conseguido essa pequena vitória, a posteriori, sob uma boa parte daqueles que a combateram.

POLITICS, PUNISHMENT AND SILENCING: THE MAOIST-INSPIRED OPPOSITION IN THE FACE Of RePression in Portugal (1964-1974)

АвsтRAст: This article seeks to analyze, firstly, the way Portuguese maoism deals, between 1964 and 1974, with the problems connected to the question of to talk or not to talk in prison and torture's context. Additionally, it tries to demonstrate how this theme remained in time and what kind of relations we can establish through it between torture, silence and memory. At the end, it shows how the conflicts in jail between maoists and communists were part of the dynamic of the ideological rupture that crossed both currents during these years.

KEY WORDS: New State, torture, silence, memory, maoism.

\section{NOTAS}

1 Partido pró-albanês que resultara da união em 1975 de pequenos coletivos maoístas. A face mais visível do PCP (R) era a sua frente de massas, a UDP (União Democrática Popular).

2 Sobre o modo como o novo poder democrático lidou, a partir de 1974, com o passado ditatorial, cf. Pinto (2004, p. 87-108); Rosas, F.; Pimentel; Madeira; Farinha e Rezola ( 2009, p. 216-270).

3 Afonso Albuquerque regista os resultados da amostra a 50 ex-presos políticos, entrevistados nos anos de 1974 e 1975 pelo Grupo de Estudo da Tortura. Em situação de interrogatório, a privação do sono foi usada em $96 \%$ dos casos. Seguiam-se, segundo o mesmo estudo, o espancamento, em 46\%; a tortura da "estátua", em 38\%; os insultos e chantagens, em 30\%; as variações de temperatura, em $8 \%$; o uso de altofalantes com gravações, também em $8 \%$; e os choques elétricos com um aguilhão para gado, em 4\% ( AlbuQuerque, 1987).

4 Cf. Comissão Nacional de Socorro aos Presos Políticos. Presos políticos. Documentos 1970-1971. Porto: Afrontamento, 1972; Comissão Nacional de Socorro aos Presos Políticos. Presos políticos. Documentos 1972-1974. Lisboa: Iniciativas Editoriais, 1975.

5 O livro-testemunho de Pinto de Sá motivou um dos poucos debates públicos que se conhecem sobre a "questão do porte", em jornais e blogues, mas sem se ultrapassar, contudo, a chamada de atenção ao carácter compungido do livro e o debate em torno da comparação entre o tipo de colaboração ativa e voluntária de Pinto de Sá com outros tipos de prestação de declarações na polícia política. De menor alcance, mas instigador de um debate mais interessante, foi a publicação no blogue Caminhos da Memória de um longo texto de análise sobre o assunto, da 
autoria de Diana Andringa, e que deu azo a dezenas de comentários (ANDRINGA, 2009).

6 ANTT-PIDE/DGS, PC 338/74, NT 6394, volume 1. Agradeço a Paula Godinho a chamada de atenção para esses elementos do processo. A alteração das datas dos autos foi também denunciada em pleno tribunal por Sérgio d'Espiney. Afirmou então que o agente Varela lhe disse ser hábito alterar as datas dos autos. ANTTPIDE/DGS, PC 1397/67, NT 5933, v. 2, fl. 395.

7 Ao longo do tempo, o Estado Novo serviu-se de uma rede de cadeias políticas destinadas ao cumprimento das penas impostas. O regime começou por dispor do presídio de Angra do Heroísmo, mas rapidamente alargou a sua rede carcerária: Cadeia do Aljube, Colónia Penal de Cabo Verde, no Tarrafal, Cadeia de Peniche e Forte de Caxias. Neste último estabelecimento - que passou a dispor de um reduto sul a partir de 1971 - funcionava também o hospital-prisão e o centro de interrogatórios da polícia política. No período de prisão preventiva, os elementos do sexo masculino podiam ficar nas delegações da PIDE de Coimbra e Porto, mas habitualmente eram transferidos para Lisboa, ficando no Aljube ou em Caxias, onde também estavam mulheres já condenadas. Depois de condenados, os homens presos eram transferidos para Peniche.

\section{REFERÊNCIAS DOCUMENTAIS}

1. Arquivo Nacional da Torre do Tombo/Arquivo da PIDE/DGS

PC 679/68, NT 6007.

PC 1397/67, NT 5933.

PC 2645/65, NT 5795-5796.

2. Arquivo Histórico-Militar

$4^{\circ}$ TMT-Lisboa, proc. 118/76.

3. Centro de Documentação 25 de abril

As lutas dos revolucionários portugueses no interior das prisões, A Vanguarda, 1970.

Comunicado sobre as prisões de agosto-setembro de 1972, CCR (m-1), fevereiro de 1973.

Defesa de Rui d'Espiney, documento policopiado, s.d.

Luta Popular, 1973.

O Novo Militante, 1973-1974.

O Bolchevista, 1970-1971.

Relatório da Comissão de Inquérito à $5^{a}$ Reunião Plenária do Comité Central, Comissão de Inquérito, s.d. 
Viva a luta dos revolucionários nas masmorras da burguesia!, Federação de Estudantes Marxistas-Leninistas, 19/9/1972.

4. Entrevistas ao autor

Baptista, Pedro. Porto, 16/1/2008.

D’espiney, Rui. Setúbal, 1/7/2008.

GonçAlves, Rita. Lisboa, 17/1/2008.

Henriques, Rui Teives. Lisboa, 3/1/2008.

Rodrigues, Francisco Martins. Lisboa, 29/1/2008.

\section{REFERÊNCIAS}

Achino-Loeb, M-L. (Ed.). Silence. The currency of power. New York/Oxford: Berghahn Books, 2006.

Albuquerque, A. Stress - causas, prevenção e controle - um guia prático. Lisboa: Informação e Saúde, Texto Editora, 1987.

ANDringA, D. Falar na polícia, blogue Caminhos da memória. Disponível em: http:// caminhosdamemoria.files.wordpress.com/2009/01/falar_dandringa1.pdf. Acesso em: 25/8/2009.

Bernardes, F. M. Uma fortaleza da resistência. Peniche 1934-1974. Lisboa: Edições Avante!, 1991.

Bourdieu, P. A ilusão biográfica. In: Ferreira, M. de M.; Amado, J. Usos e abusos da história oral. Rio de Janeiro: Fundação Getúlio Vargas, 2006. p. 183-192.

BRANCHE, R. Género y tortura: cuando una mujer pregunta a los hombres sobre la violencia. Historia, antropologia y fuentes orales, n. 26, p. 37-46, 2006.

Catroga, F. Memória, história e historiografia. Coimbra: Quarteto, 2001.

Comissão Nacional de Socorro aos Presos Políticos. Presos políticos. Documentos 1970-1971. Porto: Afrontamento, 1972.

Comissão Nacional de Socorro aos Presos Políticos. Presos políticos. Documentos 1972-1974. Lisboa: Iniciativas Editoriais, 1975.

Madeira, J. et al. Vítimas de Salazar. Estado Novo e violência política. Lisboa: A Esfera dos Livros, 2007.

Martins, H. Portugal. Classe, status e poder. Lisboa: ICS, 1998.

Metello, P. Perez Metello. 44 anos, jornalista. Jornal Público, n. 1507, 22/4/1994.

Oliveira, V. de. Veiga de Oliveira. 65 anos, engenheiro. Jornal Público, n. 1507, 22/4/1994.

Orwell, G. Mil novecentos e oitenta e quatro. Lisboa: Antígona, [1949]1997. 
Pereira, J. P. Álvaro Cunhal, uma biografia política - Daniel, o jovem revolucionário. Sacavém: Temas e Debates, 1999. v. 1.

Pimentel, I. F. A história da PIDE. Lisboa: Temas e Debates/Círculo de Leitores, 2007.

Pinto, A. C. Ajustando contas com o passado na transição para a democracia em Portugal. In: Brito, A. B. de; González-Enríquez, C.; Fernández, P. A. Política da memória. Verdade e justiça na transição para a democracia. Lisboa: ICS, 2004. p. 87-108.

Pollak, M. Une identité blessée: études de sociologie et d'histoire. Paris: Editions Métailie, 1993.

Rodrigues, F. M. Os anos do silêncio. Lisboa: Dinossauro/Abrente, 2008.

Rosas, F. et al. Tribunais políticos. Tribunais militares especiais e tribunais plenários durante a Ditadura e o Estado Novo. Lisboa: Temas e Debates, 2009.

SÁ, P. de. Conquistadores de almas. Lisboa: Guerra e Paz, 2006.

SCARry, E. The body in pain. The making and unmaking of the world. Oxford: Oxford University Press, 1985.

Sironi, F. Bourreaux et victimes. Psychologie de la torture. Paris: Odile Jacob, 1999.

Thomson, A. Anzac memories. Putting popular memory theory into practice in Australia. In: Perks, R; Thomson, A. (Ed.). The oral history reader. Routledge: Londres e Nova Iorque, [1990]2006. p. 244-254.

Valente, J. P. João Pulido Valente. 63 anos, médico. Jornal Público, n. 1507, 22/4/1994.

WEINE, S. Testimony after catastrophe. Narrating the traumas of political violence. S.l.: Northwestern University Press, 2006. 